\title{
Uncertainty in Teaching Health Center (THC) Funding: Still Crazy After All These Years
}

\author{
Joseph W. Gravel, Jr., MD (J Am Board Fam Med 2017;30:275-278.)
}

Fifty years ago, H. Jack Geiger and Count Gibson recognized an unmet societal need for basic health care services-ironically, near Boston's renowned academic medical centers-and started the nation's first community health center (CHC). That same year (1965), at a time when half the physicians in the United States were providing primary care services, Medicare graduate medical education (GME) funding was established to ensure an adequate physician workforce for health care access. Despite $\$ 14$ billion of taxpayer money invested in GME annually, $>65$ million Americans currently live in what are officially deemed primary care shortage areas. ${ }^{1}$ From 1998 to 2006, the number of counties with medically disenfranchised populations_-defined as "people with no or inadequate access to a primary care physician due to a local shortage of such physicians"-increased by $52 \%{ }^{2}$ With no specific incentives nor requirements for teaching hospitals to produce a balanced workforce of primary care physicians and specialists, local profit motives supersede general societal needs. Currently, the Centers for Medicare \& Medicaid Services (CMS) GME operates in large part as a subsidy for more financially lucrative, procedure-oriented specialties. Although a proven alternative model currently exists for producing a primary care workforce where it is needed most, the innovative Teaching Health Center (THC) GME program is at risk and continues to face funding uncertainty and damaging instability.

From the Greater Lawrence Family Health Center, Lawrence, MA.

Funding: none.

Conflict of interest: none declared.

Corresponding author: Joseph W. Gravel, Jr., MD, Greater Lawrence Family Health Center, 34 Haverhill St, Lawrence, MA 01841 (E-mail: jgravel@glfhc.org).

\section{See Related Article on page 279.}

\section{Why Funding Uncertainty Is Unworkable in GME}

The study by Kurz et $\mathrm{al}^{3}$ in this issue clearly demonstrates the negative impact of uncertainty in THC GME funding on position growth between 2011 and 2015. With the Affordable Care Act's Teaching Health Center GME provision, extant programs like the Lawrence Family Medicine Residency in Lawrence, MA expanded and new ones were established. The per-resident amount was set at $\$ 150,000$ by the Health Resources and Services Administration. In the late fall of 2013, with the Affordable Care Act's THC provision scheduled to expire in 2015, THC residencies had a decision to make: recruit the same class size for academic year 2014-2015, or reduce it despite demonstrated community need and a national shortage of primary care physicians. Given the uncertainty of any continued THC GME funding, our THC program made the difficult choice to reduce the size of its next residency class. Other programs were forced to not recruit at all.

In the non-GME world, if employees are hired and funding is subsequently cut (or revenues decline), an organization can reduce its workforce through attrition or layoffs. With a GME program, however, this is not a viable option, as the program cannot selectively "cull the herd" by laying off well-performing residents; fittingly, policies from the Accreditation Council for Graduate Medical Education and the American Board of Family Medicine discourage this. GME expense is prospectively committed for 3 to 5 years (the program's training period), whereas the governmental funding commitment for GME not funded by the CMS is not. Funding uncertainty resulted in reducing the size of our program in 2014, an effect that persists to this day as the class of 2018 begins their required fourth year of residency as part of the Accreditation Council for Graduate Medical Education Length of Training pilot. Nationally, THC funding uncer- 
tainty has effectively eliminated 165 primary care positions, as 742 THC residents train despite 907 approved (but potentially unfunded) THC GME resident slots.

The wild fluctuations in THC GME funding our health center receives has been another budgeting challenge. Originally set at $\$ 150,000$, the per-resident amount ranged from potentially $\$ 0$ with the sunsetting of 5-year ACA provision, to $\$ 95,000$ with the Medicare Access and CHIP Reauthorization Act of 2015 , to $\$ 116,000$ (still $\$ 40,000$ below actual cost) in 2017 . This latest increase was bittersweet, a direct result of other THCs cutting positions because of funding uncertainty, resulting in budgeted Health Resources and Services Administration funds being left unused and subsequently redistributed. Even for a relatively small complement of THC residents (6 in our case), the difference in the funding our program received was $\$ 330,000$ (when the per-resident amount was cut from $\$ 150,000$ to $\$ 95,000)$. For many THCs-particularly newer programs with less of a track record to reassure their CHCs of their residencies' financial feasibility - continuing to produce primary care physicians was deemed too risky and financially imprudent.

Where does one cut $\$ 330,000$ (or more) from a CHC budget to keep a commitment to matched residents and their families? CHCs almost universally have limited financial reserves and live on small margins. Residency startup costs, included in the ACA but never funded by Congress, are also problematic to justify to a CHC board of directors when legislators are unwilling to commit long-term support through a permanent funding mechanism. Creating a situation that makes it virtually impossible to plan a budget for existing programs stifles the willingness and ability of potential new THCs to jump into the pool.

\section{Why THCs Are Needed to Meet Workforce and Societal Needs}

What does the health care system get out of THCbased residency training? Can we not just do the same thing and hope for better results with a hospital-only GME payment system? Lessons from the Massachusetts experience show the answer is clearly no.

Our CHC has produced 165 board-certified family physicians - more than all the Boston teach- ing hospitals combined. After 50 years, it is clear that an Academic Health Center (AHC)-dominated GME system does wondrous things with research and subspecialty care, but has been an abject failure in (1) producing an adequate primary care workforce that serves societal needs; (2) connecting the medical-industrial complex with the needs of the community and addressing social determinants of health; (3) providing access to millions of Americans who do not live in urban areas, where AHCs are generally located; and (4) training physicians using a cost-effective, value-oriented, fully actualized, interdisciplinary model.

THC GME provides service where it is needed most; $>70 \%$ are located in federally designated high-need areas ${ }^{4}$ that still exist despite CMS GME. Among patients in CHCs, $62 \%$ are racial or ethnic minorities and $93 \%$ have a low income; THC GME directly addresses health disparities. ${ }^{5}$ Social accountability in the THC GME program exceeds that in the CMS GME, as $91 \%$ of THC graduates remain in primary care practice (only $23 \%$ for CMS GME); most practice in underserved communities after graduation $(80 \%$, vs $26 \%$ in $\mathrm{CMS}$ GME), and $19 \%$ practice in rural America, compared with only $8 \%$ of CMS GME graduates. ${ }^{6}$ THC residencies also serve as a magnet for talented family physicians wanting to teach as part of their professional lives. A "medical desert" in Lawrence, MA, has grown to include 72 primary care physicians, 21 nurse practitioners and physician assistants, and 37 residents.

Finally, hospital-based GME produces what hospitals need, not necessarily what the health care system needs. In the 2017 National Resident Matching Program (NRMP), despite a persistent shortage of family physicians, general surgeons, and psychiatrists, Massachusetts' teaching hospitals sponsored only 35 family medicine positions, 51 general surgery positions, and 79 psychiatry positions - these numbers have changed little over the past 10 years. Conversely, in a state and nation with no apparent anesthesiologist, pathologist, or radiologist shortage, Massachusetts teaching hospitals offered 131 positions in Anesthesiology, 40 in $\mathrm{Pa}$ thology, and 74 in Radiology. ${ }^{7}$ Despite a Massachusetts Medical Society Workforce Study showing family medicine as a critical shortage specialty, ${ }^{8}$ and a Massachusetts Special Commission on GME Report defining specialties with critical shortages, of the 1369 NRMP residency positions offered in 
Massachusetts in 2017, only 3.3\% were offered in Family Medicine, $3.7 \%$ in General Surgery, and $5.8 \%$ in Psychiatry.

\section{Implications for Policymakers and the THC Movement \\ Stable and Permanent THC Funding}

In a tight fiscal environment, this means taking another look at what the nation is getting for its CMS GME, redirecting funding away from second certificate programs in which hospitals quickly recoup their training-related costs through clinical revenues, and directing them to programs such as THC GME. Given that the median net cost of training a resident in a THC is $\$ 157,602$ in fiscal year $2017,,^{10}$ an annual per-resident amount tied to a comparable percentage of average national CMS GME reimbursement should be established and reliably funded.

\section{Stability for Medicaid GME}

Medicaid GME is an additional funding mechanism at the state level, but it is also unreliable. For example, in 2008, in the midst of a budget crisis, Massachusetts eliminated Medicaid GME, which disproportionately affected primary care residency programs with a large percentage of Medicaid patients. Our health center incurred a $\$ 800,000$ loss overnight (approximately $25 \%$ of the entire residency budget). Federal Medicaid funding to states should require a THC GME funding component.

\section{Bend the Cost Curve}

Training in a higher- or lower-cost hospital referral region has been shown to have an imprinting effect for up to 15 years after residency ${ }^{11}$; this phenomenon may also apply to training in facilities with a lower overall cost of care, such as THCs, and should be studied.

\section{Transparency and Accountability}

The social accountability of all GME programs should be measured, reviewing graduates' specialties and practice locations, and the programs' services to surrounding communities. ${ }^{12}$ With care moving out of hospitals, GME funds should also follow trainees into all training settings, rather than being linked to the location of service relative to the sponsoring institutions.

\section{Conclusion}

Numerous reports from eminent committees have been written detailing recommendations to make GME more accountable to the public and modernized in order to best achieve the "Triple Aim." ${ }^{, 13-15}$ Gail Sullivan ${ }^{16}$ wrote about the "Tragedy of the Medical Education Commons," in which the pursuit of individual economic self-interest ultimately destroys the collective good. GME's "season of accountability and social responsibility" demands CMS GME reform, in addition to a complementary permanent THC GME system that should be readily embraced by both sides of the political aisle. Making THC GME a permanent component of the GME landscape would provide increased accountability and value for the collective good.

To see this article online, please go to: http://jabfm.org/content/ 30/3/275.full.

\section{References}

1. Bodenheimer T, Pham H. Primary care: current problems and proposed solutions. Health Aff (Millwood) 2010;29:799-805.

2. National Association of Community Health Centers; Robert Graham Center. Access denied: a look at America's medically disenfranchised. 2007. Available from: http://www.graham-center.org/content/dam/ $\mathrm{rgc} /$ documents/publications-reports/monographsbooks/Access\%20Denied.pdf. Accessed March 27, 2017.

3. Kurz T, Liaw W, Wingrove P, Petterson S, Bazemore A. Funding instability reduces the impact of the Teaching Health Center Graduate Medical Education program. J Am Board Fam Med 2017;30: $279-80$.

4. Butkus R, Lane S, Steinmann A, et al. Financing U.S. graduate medical education: a policy position paper of the Alliance for Academic Internal Medicine and the American College of Physicians. Ann Intern Med 2016;165:134-7.

5. Blanchard J, Petterson S, Bazemore A, Watkins K, Mullan F. Characteristics and distribution of graduate medical education training sites: are we missing opportunities to meet U.S. health workforce needs? Acad Med 2016;91:1416-22.

6. Ku L, Mullan F, Serrano C, Barber Z, Shin P. Teaching health centers: a promising approach for building a primary care workforce for the 21 st century. Policy research brief no. 40. Washington, DC: Department of Health Policy and Management; The George Washington University Milken Institute School of Public Health; 2015. Available from: http://publichealth.gwu.edu/pdf/eIR/GGRCHN_ 
PolicyResearchBrief_40.pdf. Accessed March 27, 2017.

7. National resident matching program match outcomes for all institutions by state 2017 . Registration, ranking and results - 2017 main residency match: 23-6.

8. Massachusetts Medical Society's 2013 Physician Workforce Study shows physician shortages, difficulty in recruiting. September 17, 2013. Available from: http://www.massmed.org/News-and-Publications/MMS-News-Releases/Massachusetts-MedicalSociety-s-2013-Physician-Workforce-Study-ShowsPhysician-Shortages,-Difficulty-in-Recruiting/ \#.WK47Hof2aM9. Accessed March 27, 2017.

9. Commonwealth of Massachusetts Executive Office of Health and Human Services. Report of the Special Commission on Graduate Medical Education. July 30, 2013. Available from: http://www.mass.gov/ eohhs/docs/eohhs/gme-final-report.pdf. Accessed March 27, 2017.

10. Regenstein M, Nocella K, Jewers MM, Mullan F. The cost of residency training in teaching health centers. N Engl J Med 2016;375:612-4.

11. Chen C, Petterson S, Phillips R, Bazemore A, Mullan F. Spending patterns in region of residency training and subsequent expenditures for care provided by practicing physicians for Medicare beneficiaries. JAMA 2014;312:2385-93.
12. Reddy AT, Lazreg SA, Phillips RL, Bazemore AW, Lucan SC. Toward defining and measuring social accountability in graduate medical education: a stakeholder study. J Grad Med Educ 2013;5:439-45.

13. Council on Graduate Medical Education. Twentyfirst report. Improving value in graduate medical education. August 2013. Available from: https:// www.hrsa.gov/advisorycommittees/bhpradvisory/ cogme/Reports/twentyfirstreport.pdf. Accessed March 27, 2017.

14. Council on Graduate Medical Education. Twenty-second report. The role of graduate medical education in the new health care paradigm. November 2014. Available from: https://www.hrsa.gov/advisorycommittees/ bhpradvisory/cogme/Reports/22report.pdf. Accessed March 27, 2017.

15. The Josiah Macy Jr. Foundation. GME report 2: ensuring an effective physician workforce for the United States: recommendations for reforming graduate medical education to meet the needs of the public. May 2011. Available from: http://macyfoundation.org/ publications/publication/ensuring-an-effective-physician-workforce-for-the-united-states. Accessed March 27, 2017.

16. Sullivan GM. The tragedy of the medical education commons. J Grad Med Educ 2016;8:1-4. 